\title{
Benefícios do uso do ácido tranexâmico no tratamento do Melasma
}

\author{
Benefits of the use of tranexamic acid in the treatment of Melasma \\ Beneficios del uso de ácido tranexámico en el tratamiento del Melasma
}

Recebido: 29/11/2021 | Revisado: 04/12/2021 | Aceito: 08/12/2021 | Publicado: 16/12/2021

\author{
Larissa Almeida Silva \\ ORCID: https://orcid.org/0000-0002-5246-1592 \\ Faculdade Independente do Nordeste, Brasil \\ E-mail: larialmeidaasilva@gmail.com \\ Maria Antonia Santos Silva \\ ORCID: https://orcid.org/0000-0003-3952-3418 \\ Faculdade Independente do Nordeste, Brasil \\ E-mail: mariaantoniajem@gmail.com \\ Jeane Rocha Santos \\ ORCID: https://orcid.org/0000-0002-1398-3638 \\ Faculdade Independente do Nordeste, Brasil \\ E-mail: Jeane@fainor.com.br
}

\begin{abstract}
Resumo
As hipercromias de pele são sequelas frequentes devido alguma desordem no processo fisiológico das pessoas, dentre elas: alterações hormonais, inflamações, alergias, envelhecimento, exposição ao sol excessiva. O processo de hiperpigmentação tecidual ocorre devido a maior produção de melanina pelas células nomeada melanócitos. $\mathrm{O}$ Melasma é uma hipercromia que acomete áreas fotoexpostas do corpo, principalmente a face de mulheres em idade fértil, gerando um aspecto inestético indesejado e que afeta diretamente a autoestima. $\mathrm{O}$ ácido tranexâmico tem se mostrado um despigmentante eficiente no clareamento da pele das pessoas melhorando consequentemente a qualidade de vida das mesmas. Trata-se de uma revisão integrativa de literatura, teve como fonte de dados artigos científicos já existentes na plataforma online. Foram feitas buscas através dos descritores: melasma, ácido tranexâmico, hiperpigmentação, em bases eletrônicas, que abordem o tema deste estudo: Pesquisas experimentais que compravam a eficácia do ativo ATX em sua concentração pura, e com combinações clareadoras, através dos métodos injetáveis, via oral e microagulhamento, proporcionando a redução de discromias pigmentares, podendo melhorar os resultados e qualidade de vida das pessoas. Embora existam poucos estudos e voluntários acerca da temática. Conclui-se que o ácido tranexâmico é uma ativo antiangiogênicos e com potencial ação clareadora que podem ser administrados por via tópica, oral e injetável, além de ser considerad seguro. Ademais, ressalta-se a importância de mais pesquisas relacionadas ao tema que possam contribuir para a criação de protocolos seguros com o uso da substância pelos profissionais.
\end{abstract}

Palavras-chave: Melasma; Hipercromia; Ácido Tranexâmico.

\begin{abstract}
The skin hyperchromias are frequent sequels due to some disorder in the physiological process of people, among them, hormonal changes, inflammation, allergies, aging, excessive sun exposure. The process of tissue hyperpigmentation occurs due to the increased production of melanin by cells called melanocytes. Melasma is a hyperchromia that affects photo exposed areas of the body, especially the face of women in fertile age, generating an unwanted unaesthetic aspect that directly affects self-esteem. Tranexamic acid has been shown to be an efficient depigmenting agent to lighten people's skin, consequently improving their quality of life. This is an integrative literature review, using as a source of data existing scientific articles in the online platform. Searches were made using the descriptors: melasma, tranexamic acid, hyperpigmentation, in electronic databases, which address the subject of this study: Experimental research that comprove the effectiveness of ATX active in its pure concentration, and with bleaching combinations, through the injectable methods, orally and microagulation, providing the reduction of pigmentary dyschromias, and may improve the results and quality of life of people. Although there are few studies and volunteers about the theme. It is concluded that tranexamic acid is an antiangiogenic active and with potential whitening action that can be administered topically, orally and injected, besides being considered safe. Furthermore, we emphasize the importance of further research related to the topic that can contribute to the creation of safe protocols with the use of the substance by professionals.
\end{abstract}

Keywords: Melasma; Hyperchromia; Tranexamic Acid. 


\begin{abstract}
Resumen
Las hipercromías cutáneas son secuelas frecuentes debidas a algún trastorno en el proceso fisiológico de las personas, entre ellos, cambios hormonales, inflamaciones, alergias, envejecimiento, exposición excesiva al sol. El proceso de hiperpigmentación de los tejidos se produce debido al aumento de la producción de melanina por parte de unas células llamadas melanocitos. El melasma es una hipercromía que afecta a las zonas fotoexpuestas del cuerpo, especialmente al rostro de las mujeres en edad fértil, generando un aspecto antiestético no deseado que afecta directamente a la autoestima. El ácido tranexámico se ha mostrado como un despigmentante eficiente en el clareamento de la piel de las personas mejorando consecuentemente la calidad de vida de las mismas. Se trata de una revisión bibliográfica integradora, que tuvo como fuente de datos los artículos científicos existentes en la plataforma online. Se realizaron búsquedas a través de los descriptores: melasma, ácido tranexámico, hiperpigmentación, en bases de datos electrónicas, que abordan el tema de este estudio: Investigaciones experimentales que comprueban la eficacia del ATX activo en su concentración pura, y las combinaciones con el blanqueo, a través de métodos inyectables, orales y microagulantes, proporcionando la reducción de las discromías pigmentarias, pudiendo mejorar los resultados y la calidad de vida de las personas. Aunque hay pocos estudios y voluntarios sobre el tema. Se concluye que el ácido tranexámico es un activo antiangiogénico y con un potencial clarificador que puede ser administrado por vía tópica, oral e injetável, además de ser considerado seguro. Además, se destaca la importancia de realizar más investigaciones relacionadas con el tema que puedan contribuir a la creación de protocolos seguros con el uso de la sustancia por parte de los profesionales.
\end{abstract}

Palabras clave: Melasma; Hipercromía; Ácido Tranexámico.

\title{
1. Introdução
}

A palavra Melasma, deriva do grego, onde melas significa negro. É considerada uma hipercromia adquirida, comum, que acomete principalmente regiões fotoexpostas ao sol, como a face e sendo menos comum no pescoço e nos antebraços (Nicolaidou \& Katsambas, 2014). A produção exagerada de melanina pode gerar uma desordem na pigmentação cutânea, levando ao surgimento das hipercromias. Tais manchas podem se originar devido ao: envelhecimento, alterações hormonais, inflamações, alergias e exposição solar, dentre outros. Dentre as principais hipercromias localizadas destaca-se o Melasma (Gonchoroski \& Corrêa, 2005).

O melasma se caracteriza por manchas simétricas, de cor castanha e de contornos irregulares (Miot et al., 2009). Mesmo que os fatores que levam ao surgimento do melasma não sejam totalmente esclarecidos, acredita-se que a exposição à luz ultravioleta, luz visível, fatores genéticos, bem como influências hormonais, sejam as principais causas para o seu aparecimento (Barbosa \& Guedes, 2018).

De acordo com Miot (2009), geralmente não se consegue resultados satisfatórios no tratamento do Melasma devido a recorrência das lesões e pela carência de um recurso que promova um clareamento decisivo, porém algumas pesquisas demonstram que a fotoproteção e uso de substâncias clareadoras são algumas alternativas de tratamento. O ácido Tranexâmico é uma das substâncias que vem sendo estudada como alternativa para o tratamento do Melasma. Segundo Padhi e Pradhan (2015), o ácido tranexâmico possui uma ação clareadora da pele e tem sido utilizado de maneira tópica ou injetável, e, atualmente também por via oral. No tratamento do Melasma ele tem se mostrado satisfatório.

Para Nasrollahi (2019), quando a pele se apresenta sem lesões e saudável, isso impacta positivamente na sua relação com outras pessoas, facilitando o seu desenvolvimento em todas as áreas da vida: social, emocional, financeiro e sexual. No entanto, quando a pele sofre com algum acometimento, isso pode impactar negativamente na sua vida. As hipercromias, tais como o Melasma, promovem um transtorno e impactam negativamente na autoestima do paciente, o que pode gerar, desde um estresse emocional, ansiedade, doenças sistêmicas e até depressão (Avram et al., 2008).

Diante do exposto, este estudo apresenta como objetivo avaliar os benefícios do ácido tranexâmico no tratamento do Melasma. 


\section{Metodologia}

Este estudo trata-se de uma revisão de literatura, que segundo Alves e Mazzotti (2002), atribui-se a dois objetivos: Construir a contextualização de um problema e analisar as alternativas existentes na literatura examinadas para a criação do referencial teórico da pesquisa. Além disso, se encarrega de ser caráter de uma pesquisa descritiva exploratória, já que se trata de um tema pouco estudado, ou explorado (Gil, 2010). Foram buscados através do melasma, ácido tranexâmico, hiperpigmentação, em bases eletrônicas, tais como: a Scientific Eletronic Library Online - Scielo, Bireme, e Google acadêmico que abordem o tema deste estudo, através de uma revisão de literatura. Os artigos serão selecionados a partir da leitura da revisão e da introdução do mesmo. Como critérios de inclusão foram adotados: artigos que abordem a temática em questão e artigos publicados entre os anos de 2005 a 2020. Como critérios de exclusão: não foram selecionados artigos que não tinham ligação com o tema e que tenham sido publicados anteriormente ao ano de 2005. A análise dos dados obtidos foi realizada através de um quadro onde se possibilitou organizar os dados dos artigos em: autor, tema, objetivo, métodos, resultados, e ano de publicação. Desta maneira, ficará mais claro e objetiva a abordagem da temática. Também foi feita uma análise descritiva, qualitativa e comparativa dos dados obtidos sobre a temática abordada. O estudo seguiu os aspectos éticos dispostos na Lei de Direitos Autorais: Lei $\mathrm{n}^{\circ}$ 9.610, de fevereiro de 1998, assegurando que as literaturas que serão utilizadas no estudo serão referenciadas corretamente, evitando assim, copias e plágios.

\section{Resultados e Discussão}

Vinte artigos foram selecionados a partir da leitura da revisão e da introdução do mesmo, porém apenas 6 se enquadraram totalmente nos critérios de inclusão e exclusão. Os dados dos estudos foram alocados em um quadro que possibilitou organizar os dados dos artigos. Desta maneira, a organização foi mais objetiva em relação a abordagem da temática. Os dados dos artigos selecionados foram distribuídos em: Título, Autor/ano, objetivos, métodos, resultado. Conforme apresentado no Quadro 1. 
Quadro 1. Artigos segundo título, autores e ano de publicação, objetivos, métodos e principais resultados. Vitória da Conquista, Bahia, Brasil. 2021.

\begin{tabular}{|c|c|c|c|c|}
\hline Título & Autor/Ano & Objetivos & Métodos & Resultados \\
\hline $\begin{array}{l}\text { Estudo de avaliação da } \\
\text { eficácia do ácido } \\
\text { tranexâmico tópico e } \\
\text { injetável no tratamento } \\
\text { do melasma. }\end{array}$ & Steiner et al. (2009) & $\begin{array}{l}\text { Avaliar a eficácia e a segurança do at } \\
\text { no tratamento de melasma, } \\
\text { comparando utilização } r \text { de } \\
\text { microinjeção localizada } \\
\text { tratamento tópico. }\end{array}$ & $\begin{array}{l}\text { Trata-se de um } \\
\text { ensaio clínico } \\
\text { aberto, } \\
\text { comparativo. }\end{array}$ & $\begin{array}{l}\text { Embora a avaliação clínica subjetiva tenha } \\
\text { demonstrado superioridade do tratamento injetável, } \\
\text { na avaliação objetiva, ambos os tratamentos } \\
\text { revelaram-se signifi cativamente efi cazes, o que } \\
\text { indica que o at é uma nova e promissora opção } \\
\text { terapêutica para o melasma. }\end{array}$ \\
\hline $\begin{array}{l}\text { Tratamento do melasma: } \\
\text { revisão sistemática. }\end{array}$ & Steiner et al. (2009) & $\begin{array}{l}\text { Realizar revisão sistemática da } \\
\text { literatura para identificar os } \\
\text { tratamentos mais eficazes e seguros } \\
\text { para o melasma, incluindo os tópicos, } \\
\text { os orais e os procedimentos. }\end{array}$ & $\begin{array}{c}\text { Revisão } \\
\text { Sistemática. }\end{array}$ & $\begin{array}{l}\text { Na autoavaliação, no grupo A, } 37,5 \% \text { das pacientes } \\
\text { classificaram como boa e } 50 \% \text {, como } \\
\text { imperceptível. No grupo B, } 66,7 \% \text { classifi caram } \\
\text { como boa e } 33,3 \% \text {, imperceptível. A avaliação } \\
\text { colorimétrica revelou melhora significativa nos } \\
\text { tratamentos. }\end{array}$ \\
\hline $\begin{array}{l}\text { A utilização do ácido } \\
\text { tranexâmico } \\
\text { tratamento de melasma. }\end{array}$ & $\begin{array}{c}\text { Daniela de Sousa } \\
\text { Lopes; Ana Cláudia } \\
\text { Calazans da Silva. } \\
\text { (2017) }\end{array}$ & $\begin{array}{l}\text { O presente estudo tem como objetivo } \\
\text { reunir dados científicos que } \\
\text { demonstrem a eficácia da utilização } \\
\text { do ácido tranexâmico no tratamento } \\
\text { de melasma }\end{array}$ & $\begin{array}{c}\text { Revisão } \\
\text { Bibliográfica }\end{array}$ & $\begin{array}{l}\text { O uso do ácido tranexâmico é eficaz no tratamento } \\
\text { do melasma, disfunção que atinge grande parte da } \\
\text { população feminina, tanto para clareamento das } \\
\text { manchas quanto para prevenção das pigmentações } \\
\text { causadas por radiação uv. }\end{array}$ \\
\hline $\begin{array}{l}\text { Microagulhamento com } \\
\text { uso de ácido } \\
\text { tranexamico para o } \\
\text { tratamento de melasma. }\end{array}$ & $\begin{array}{c}\text { Stephane do } \\
\text { Nascimento Silva } \\
\text { (2018) }\end{array}$ & $\begin{array}{l}\text { Este estudo objetivou reunir dados } \\
\text { científicos que demonstraram a } \\
\text { eficácia da utilização do ácido } \\
\text { tranexâmico associado à técnica de } \\
\text { microagulhamento no tratamento de } \\
\text { melasma. }\end{array}$ & $\begin{array}{c}\text { Levantamento } \\
\text { bibliográfico }\end{array}$ & $\begin{array}{l}\text { Associado ao microagulhamento, o ácido } \\
\text { tranexâmico visa reduzir a síntese de melanina, } \\
\text { inibir a formação de melanossomas ocasionando na } \\
\text { sua degradação, atuando na pigmentação cutânea, } \\
\text { impedindo a melanogênese e o transporte de } \\
\text { melanina para os queratinócitos, ou seja, "quela } \\
\text { íons de cobre e ferro e promove a descamação } \\
\text { epidérmica". }\end{array}$ \\
\hline $\begin{array}{l}\text { Tratamento estético para } \\
\text { o melasma: revisão de } \\
\text { literatura }\end{array}$ & $\begin{array}{l}\text { Elisângela da Silva } \\
\text { Rufino, Pamella matos } \\
\text { Guimarães, Orlando } \\
\text { Izolani (2020) }\end{array}$ & $\begin{array}{l}\text { Esse estudo tem como objetivo } \\
\text { elucidar as intervenções terapêuticas } \\
\text { estéticas preconizadas para tratar o } \\
\text { melasma, na atualidade. }\end{array}$ & $\begin{array}{c}\text { Revisão } \\
\text { sistemática }\end{array}$ & $\begin{array}{l}\text { Foi possível concluir que a hidroquinona foi a } \\
\text { substância com maior potencial para a remissão dos } \\
\text { sinais característicos da disfunção estética, } \\
\text { especialmente quando associada a outros fármacos, } \\
\text { foi a técnica mais aceita na literatura. }\end{array}$ \\
\hline $\begin{array}{l}\text { Ácido Tranexâmico no } \\
\text { tratamento de melasma. }\end{array}$ & $\begin{array}{c}\text { Rosana Pacheco Reis } \\
\text { (2020) }\end{array}$ & $\begin{array}{l}\text { Investigar as formas alternativas de } \\
\text { uso do ácido tranexâmico (atx) no } \\
\text { tratamento do melasma através de } \\
\text { uma revisão bibliográfica descritiva }\end{array}$ & $\begin{array}{l}\text { Revisão } \\
\text { bibligráfica } \\
\text { descritiva. }\end{array}$ & $\begin{array}{l}\text { Concluindo-se que a pesquisa apresentada indica } \\
\text { que o tratamento com aplicação do atx são seguros } \\
\text { e eficazes para o tratamento do melasma, havendo a } \\
\text { necessidade de maiores estudos clínicos para a } \\
\text { determinação das condições terapêuticas ideais. }\end{array}$ \\
\hline
\end{tabular}

Fonte: Dados da pesquisa.

As diversas tonalidades de cores da pele são definidas principalmente pela presença da melanina, um pigmento castanho denso, de alto peso molecular que, quando mais concentrado, assume aspecto enegrecido (Medeiros et al., 2016). O Melasma tem sido uma discromia que tem características máculas acastanhadas, com contornos irregulares, limites nítidos, nas áreas foto expostas, especialmente face. É uma patologia que remete ambos os sexos e todas as raças. É mais comum no sexo feminino e principalmente em gestantes, particularmente em indivíduos com fototipos altos (Kontze \& Bianchetti, 2018).

As principais características do melasma são manchas escurecidas, mas observou que os pacientes com melasma têm características diferentes como eritema telangiectático pronunciado confinado ao melasma lesa pele Kin et al (2007).

Embora o melasma não esteja completamente desvendado, existem vários fatores que podem estar implicados com seu surgimento, tais como: nível elevado do hormônio luteinizante (LH) e os baixos níveis de estradiol. E em relação à localização do pigmento, pode ser epidérmico, dérmico ou misto (Steiner et a., 2009). Além disso, atualmente os estudos indicam que há uma relação entre a vascularização cutânea e melanogênese. Tal fato ocorre devido aos receptores de fator do crescimento endotélio vascular (VEGF) presentes no melanócito, que seriam capazes produzir respostas a fatores angiogênicos, tendo como resultado o aumento da vascularização, o que favorece o surgimento da hiperpigmentação cutânea (Miot et al., 2009).

Diante do exposto acima, o ácido tranexâmico tem se apresentado como uma importante alternativa para o tratamento do melasma, uma vez que o ácido possui a capacidade de alterar mudanças dérmicas anormais relacionadas ao melasma, tal como o aumento da vascularização. Em estudos histológicos da pele, feitos anteriomente, ficou evidenciado a diminuição do 
número de vasos sanguíneos e eritema, que pode ser considerado efeito resultante dos efeitos antiangiogênicos do ácido (Steiner et al., 2009).

Em estudo feito por Steiner (2019) que teve como objetivo avaliar a eficácia e a segurança do AT no tratamento de melasma, comparando utilização de microinjeção localizada versus tratamento tópico, através dessa avaliação clínica subjetiva, demonstrou superioridade do tratamento injetável. No entanto, na avaliação objetiva, ambos os tratamentos revelaram-se significativamente eficazes, o que indica que o ATX é uma nova e promissora opção terapêutica para o melasma. Corroborando com o resultado do estudo supracitado, está a pesquisa feita por Lopes e Silva (2017), que teve como objetivo reunir dados científicos que demonstrassem a eficácia da utilização do ácido tranexâmico no tratamento de melasma. A pesquisa revelou a eficácia do ácido tanto para o clareamento das manchas quanto para prevenção das pigmentações causadas por radiação uv.

Maeda e Nagamuga (1998) relatam que o ácido tranexâmico inibi a ligação de plasminogênio originário de células endoteliais, a queratinócitos, que pode ser um ótimo mecanismo para o tratamento melasma. Notou-se que muitos estudos procedimentais acabam incluindo o uso sincrônico de terapias tópicas e fotoproteção. (Spadafora et al, 2019).

Silva (2018) reuniu dados científicos que demonstraram a eficácia da utilização do ácido tranexâmico associado à técnica de microagulhamento no tratamento de melasma, como resultado foi observado que o ácido tranexâmico: reduz a síntese de melanina; inibe formação de melanossomas, ocasionando na sua degradação; reduz pigmentação cutânea, impedindo a melanogênese e o transporte de melanina para os queratinócitos; e ainda: "quela íons de cobre e ferro e promove a descamação epidérmica". Em estudo feito por Pinho (2020) concluiu que o microagulhamento e o ácido tranexâmico oral são seguros e traz benefícios ao tratamento do melasma, além disso, os tratamentos promoveram alterações histológicas epidérmicas e dérmicas divergentes, no qual contribuem para o discernimento dos mecanismos de clareamento do melasma.

O ácido tranexâmico pode ser administrado por via tópica, injetável e oral, e como observa Silva et al (2020) em um estudo, cujo objetivo foi elucidar as intervenções terapêuticas estéticas preconizadas para tratar o melasma na atualidade. O autor concluiu que os tratamentos com o ATX são seguros e eficazes para o tratamento do melasma, ressaltando apenas a importância de mais estudos clínicos para a determinação das condições terapêuticas ideais.

\section{Conclusão}

O melasma trata-se de uma disfunção multifatorial, porém sabe-se que o receptor VEGF produiz respostas que podem estar relacionadas ao surgimento das manchas. $O$ ácido Tranexâmicoe é uma ativo antiangiogênicos e com potencial ação clareadora que podem ser administrados por via tópica, oral e injetável, além de ser considerado seguro.

Diante do exposto, conclui-se que o ácido tranexamico é eficaz no tratamento de melasma pelos diversos benefícios apresentados acima. Ademais, ressalta-se a importância de mais pesquisas relacionadas ao tema que possam contribuir para a criação de protocolos seguros com o uso da substância pelos profissionais. Além disso considera-se se essencial que os estudos elucidem as concentrações ideiais e seguras do ácido no tratamento do melasma nos mais diversos fototipos.

\section{Referências}

Miot, L. D. B., Miot, H. A., Silva, M. G. D., \& Marques, M. E. A. (2009). Physiopathology of melasma. Anais brasileiros de dermatologia, 84, 623-635.

Nicolaidou, E., \& Katsambas, A. D. (2014). Pigmentation disorders: hyperpigmentation and hypopigmentation. Clinics in dermatology, 32(1), 66-72.

Gonchoroski, D. D., \& Corrêa, G. M. (2005). Tratamento de hipercromia pós-inflamatória com diferentes formulações clareadoras. Infarma, 17(3-4), 84-8.

Miot, L. D. B., Miot, H. A., Silva, M. G. D., \& Marques, M. E. A. (2009). Fisiopatologia do melasma. Anais brasileiros de dermatologia, 84, $623-635$.

Barbosa, K. L., \& Guedes, M. R. M. (2018). Melasma: tratamento e suas implicações estéticas. Infarma-Ciências Farmacêuticas, 30(2), 85-94. 
Research, Society and Development, v. 10, n. 16, e472101624104, 2021

(CC BY 4.0) | ISSN 2525-3409 | DOI: http://dx.doi.org/10.33448/rsd-v10i16.24104

Padhi, T., \& Pradhan, S. (2015). Oral tranexamic acid with fluocinolone-based triple combination cream versus fluocinolone-based triple combination cream alone in melasma: an open labeled randomized comparative trial. Indian Journal of Dermatology, 60(5), 520.

Nasrollahi, S. A., Nematzadeh, M. S., Samadi, A., Ayatollahi, A., Yadangi, S., Abels, C., \& Firooz, A. (2019). Evaluation of the safety and efficacy of a triple combination cream (hydroquinone, tretinoin, and fluocinolone) for treatment of melasma in Middle Eastern skin. Clinical, cosmetic and investigational dermatology, 12, 437.

Rescaroli1 ${ }^{1}$ A. C., da Silva, G. M., \& Valdameri, G. A. (2009). Foliculite e a depilação: seqüelas, tratamentos e o papel do Tecnólogo em Cosmetologia e Estética. Monografia] Balneário Camboriú: Universidade do Vale do Itajaí-UNIVALI.

Alves-Mazzotti, A. J. (2002). Repensando algumas questões sobre o trabalho infanto-juvenil. Revista Brasileira de Educação, 87-98.

Witt, A. S., \& da Silva, F. C. C. (2021). Living Labs nas Universidades Federais do Brasil. Fórum de Estudos em Informação, Sociedade e Ciência, 4, 146154.

Kontze, P. R., \& Bianchetti, P. (2018). Eficácia do ácido tranexâmico no tratamento do melasma. Revista Destaques Acadêmicos, 10(3).

Costa, A. F., Melo, D. M. A., Melo, M. A. F., Medeiros, R. L. B. A., Pimentel, P. M., Câmara, M. S. C., \& Chantelle, L. (2016). Preparação de pigmentos de aluminatos de cobalto para aplicação em vidrados cerâmicos. Cerâmica, 62, 179-185.

Steiner, D., Feola, C., Bialeski, N., de Morais, F. A., Antiori, A. C. P., Addor, F. A. S. A., \& Folino, B. B. (2009). Estudo de avaliação da eficácia do ácido tranexâmico tópico e injetável no tratamento do melasma. Surgical \& Cosmetic Dermatology, 1(4), 174-177.

Steiner, D., Feola, C., Bialeski, N., \& de Morais, F. A. (2009). Tratamento do melasma: revisão sistemática. Surgical \& Cosmetic Dermatology, 1(2), 87-94.

Kim, E. H., Kim, Y. C., Lee, E. S., \& Kang, H. Y. (2007). The vascular characteristics of melasma. Journal of dermatological science, 46(2), $111-116$.

Maeda, K., \& Naganuma, M. (1998). Topical trans-4-aminomethylcyclohexanecarboxylic acid prevents ultraviolet radiation-induced pigmentation. Journal of Photochemistry and Photobiology B: Biology, 47(2-3), 136-141.

Spadafora, Maria Claudia Fonseca de Almeida et al. Os benefícios dos despigmentantes para o tratamento do melasma e rejuvenescimento facial. Revista 34 Saúde em Foco, n. 11, 2019

Cassiano, D. P. (2021). Estudo clínico sobre eficácia, segurança e mecanismos de ação do microagulhamento e ácido tranexâmico oral no tratamento do melasma facial.

Silva, S. D. N. (2018). Microagulhamento com uso de ácido tranexamico para o tratamento de melasma. CCE cursos.

Lopes, D. d. S., \& Silva, A. C. C. d. (2017). A utilização do ácido tranexâmico no tratamento de melasma. Revista Científica da FHO, 5(1). 